\title{
Desenhar para compreender e lembrar: a arquitetura portuguesa no traço de Lucio Costa
}

\author{
José Simões Pessôa*
}

Resumo Este artigo discorre sobre os blocos de viagem feitos por Lucio Costa durante sua permanência em Portugal no ano de 1952 e ressalta a importância do croqui como ferramenta de conhecimento da arquitetura e portanto de projeto. Para a sua visão sobre a arquitetura brasileira era fundamental conhecer Portugal. É o interesse em conhecer a arquitetura portuguesa no seu local de origem que iria motivar Lucio Costa a empreender duas viagens de estudos por Portugal. A primeira ocorreu no ano de 1948, da qual só restou um relatório e da segunda, 304 desenhos distribuídos em 5 bloquinhos e 2 folhas avulsas.

Palavras-chave: Lucio Costa, arquitetura portuguesa, patrimônio, desenho.

\section{Drawing to understand and remember: the portuguese architecture in the hand drawing of Lucio Costa}

\begin{abstract}
This article discusses the travel blocks made by Lucio Costa during his stay in Portugal in 1952 and emphasizes the importance of sketching as a tool for knowledge of architecture and therefore of design. It was fundamental to him, to know Portugal in order to understand the Brazilian architecture. The interest to know the Portuguese architecture in its original place motivated Lucio Costa to undertake two trips of studies by Portugal. The first occurred in the year 1948, of which only one report remained and the second, 304 drawings distributed in 5 blocks and 2 separate sheets.
\end{abstract}

Key words: Lucio Costa, portuguese architecture, drawing.
Dibujar para entender y recordar: la arquitectura de Portugal en los trazos de Lucio Costa

Resumen Este artículo discurre sobre los bloques de viaje hechos por Lucio Costa durante su permanencia en Portugal en el año 1952 y resalta la importancia del croquis como herramienta de conocimiento de la arquitectura y por lo tanto de proyecto. Para su visión sobre la arquitectura brasileña era fundamental conocer Portugal. Es el interés en conocer la arquitectura portuguesa en su lugar de origen que motivaría a Lucio Costa a emprender dos viajes de estudios por Portugal. La primera ocurrió en el año 1948, de la cual sólo quedaba un informe y de la segunda, 304 diseños distribuidos en 5 bloquitos y 2 hojas sueltas.

Palavras clave: Lucio Costa, arquitectura portuguesa, dibujo. 
$\mathbf{P}$

ensar o papel do desenho no ensino de projeto, em especial no ensino de projeto de restauro, tem sido uma meta perseguida pelos professores desta disciplina na Escola de Arquitetura e Urbanismo da Universidade Federal Fluminense. A ideia de que para uma intervenção de restauro qualificadora é necessário que o projetista conheça profundamente a arquitetura, objeto da sua intervenção, é a diretriz para propormos um exercício preliminar de registrar os imóveis através de croquis. O desenho surge então como uma ferramenta indispensável no processo de conhecimento da arquitetura. Desenhar implica em aprender a ver, e mais do que ver, compreender o que está se vendo. No processo inicial de abordagem dos imóveis estudados na disciplina de Projeto de Restauro tem-se verificado que a fotografia, instrumento básico na fase de levantamento e diagnóstico, não contribui necessariamente para que os alunos tenham um maior conhecimento das características de escala, da modulação e dos detalhes construtivos dos edifícios. O registro fotográfico acabava por não exigir do aluno o esforço de ver, e de compreender o que estava sendo visto. Na tentativa de solucionar este problema foi introduzido na disciplina um exercício preliminar que era o de desenhar um prédio para registrar as características construtivas e de escala e da modulação. Não o desenho apurado, artístico, mas um desenho informativo, uma anotação para lembrar a informação colhida na observação atenta da arquitetura (MASSIRONI, 1983). O desenho como ferramenta de estudo e conhecimento para o arquiteto.

Esta discussão entre os professores da disciplina de projeto de restauro na Universidade Federal Fluminense ocorria em paralelo a um projeto que eu vinha desenvolvendo de identificação dos blocos de viagem feitos por Lucio Costa durante sua permanência em Portugal no ano de 1952. Estudar estes cadernos de viagem de Lucio Costa consolidou a convicção da importância do croqui como ferramenta de conhecimento da arquitetura e portanto ferramenta de projeto.

\section{A arquitetura portuguesa desenhada por Lucio Costa (PESSÔA, 1999)}

É o interesse em conhecer a arquitetura portuguesa no seu local de origem que iria motivar Lucio Costa a empreender duas viagens de estudos por Portugal. A primeira foi no ano de 1948, Lucio era o diretor de Estudos e Tombamentos do Patrimônio Histórico e Artístico Nacional. O cargo que havia sido criado três anos antes, em 1945, correspondia grosso modo as atribuições que ele já havia assumido quando da criação do Serviço do Patrimônio Histórico e Artístico Nacional (SPHAN) em 1937. Lucio na realidade funciona no SPHAN como uma espécie de consultor, opinava um pouco sobre tudo, mas principalmente era o responsável pelos pareceres finais dos processos de tombamento realizados pelo SPHAN.

*José Simões Pessôa é arquiteto, professor doutor da Universidade Federal Fluminense.
A preocupação em organizar esse trabalho levou Lucio Costa a propor em 1947 uma classificação da arquitetura civil brasileira, como instrumento metodológico para 
classificar futuros tombamentos. Essa proposta de classificação, somada aos textos, "Documentação Necessária" e "Arquitetura dos jesuítas no Brasil", ambos publicados na Revista do Patrimônio, tornavam evidente para ele a necessidade de conhecer arquitetura que havia sido produzida em Portugal contemporaneamente a nossa arquitetura colonial, estabelecendo as possíveis relações entre estas.

Os estudos na época, sobre a arquitetura colonial brasileira, produzidos pelos colaboradores da Revista do Patrimônio, procuravam entender esta como parte de um processo de transferência, modificação e retorno, entre Portugal e suas colônias. Nesta perspectiva, a arquitetura de Portugal seria a chave de leitura das características plásticas da arquitetura brasileira.

Era fundamental para a visão de Lucio Costa sobre a arquitetura brasileira, conhecer Portugal. Ele havia estado rapidamente em Lisboa quando da sua viagem para Itália nos anos 1920. Então no final dos anos 1940 e inicios dos 1950, conhecer Portugal após 10 anos trabalhando no Patrimônio Histórico e Artístico Nacional tinha se tornado uma necessidade. Ir a Portugal era ir de encontro ao nosso passado arquitetônico, aquele passado que vinha sendo cuidadosamente reconstruído nos tombamentos e restaurações dos primeiros anos de atividade do SPHAN.

Lucio obteve licença para viajar com a família, sua mulher e duas filhas, percorrendo Portugal de norte a sul. Desta viagem ele produziu um relatório, que só seria divulgado quarenta e seis anos depois com a publicação no seu livro autobiográfico.

No relatório ele anunciava não ter sido possível alcançar o objetivo pretendido, pois o estudo da arquitetura de Portugal e do Brasil não resultava no simples esquema de modelo e cópia e sim na confirmação da autenticidade de ambos. A viagem através de Portugal serviu para constatar, não exatamente uma relação de dependência artística, e sim a existência de um vocabulário comum desenvolvido com razoável autonomia nos dois lados do Atlântico. Da viagem de 1948 não restaram registros, além do citado relatório.

Razões familiares ocasionaram a retomada, em 1952, do projeto de estudo da arquitetura portuguesa. A família Costa decide realizar o tratamento de saúde de uma das filhas na Europa, chegando a Portugal, de navio, em janeiro daquele ano. Os primeiros meses são dedicados a instalação da família e só em junho que ele pôde efetivamente partir para a viagem solitária através de Portugal registrando em desenhos a arquitetura portuguesa, aquilo que ele denominava o seu "serviço". Ao todo ele produz um conjunto de 304 folhas de desenhos distribuídos em 5 bloquinhos e 2 papeis avulsos que retratam a arquitetura portuguesa nas suas mais diferentes regiões. Interessa-lhe o que se construiu depois dos descobrimentos marítimos, isto é, compreender qual o contexto geral da arte portuguesa na qual se insere a arquitetura colonial brasileira. Tudo registrado nos cinco pequenos blocos, adquiridos ao longo da viagem, de tamanhos diferentes, sendo o maior deles correspondente a um A5.

Os desenhos portugueses de Lucio Costa são fundamentalmente registros feitos para depois recordar as coisas vistas. Executados com lápis preto eram o que ele mesmo denominou de apontamentos esquemáticos e não tinham a intenção de serem apresentados a um público maior. Eram as anotações do arquiteto que com o lápis ia 
registrando as coisas significativas vistas na viagem. Uma conversa dele consigo mesmo, para compreender e lembrar do que tinha visto. Na correspondência que manteve com Rodrigo Melo Franco de Andrade, Lucio nunca menciona estar desenhando e sim "fazendo anotações".

A análise e identificar dos desenhos nas folhas permitiu compreender os códigos de organização das informações contidas nestas. Em primeiro lugar era necessário identificar as localidades, cidades e vilas a que pertenciam prédios e detalhes arquitetônicos desenhados em cada folha. Quase em todas as folhas o nome das localidades estava escrito e sublinhado para distingui-lo de outras informações escritas. Havia é claro exceções, e as informações de localização revelavam-se uma armadilha, como no caso do Mosteiro beneditino de Tibães, nos arredores de Braga. O nome surge em duas diferentes folhas desenhadas em diferentes blocos. Em nenhum dos casos porém, tratam-se de desenhos do mosteiro cujo o nome estava escrito na folha, e sim de riscos feitos a partir de detalhes de outras igrejas, o Mosteiro Beneditino de Rendulfe e a Igreja do Convento de São Gonçalo em Amarante, que apresentam soluções arquitetônicas e decorativas semelhantes a Tibães (MATTOSO, 2010).

Havia, ainda, aquelas folhas que não apresentavam anotação alguma em relação as localidades das coisas desenhadas. Nesses casos, a identificação se dava quase sempre a partir das folhas anteriores. Os desenhos eram via de regra, continuação do que havia sido desenhado antes, referindo-se a objetos na própria cidade, ou localizados nas cidades próximas.

Já a distribuição dos temas pelos desenhos espalhados nas folhas dos blocos obedece a duas regras básicas. Em muitos casos, um único tema, uma casa rural, uma igreja, etc, torna-se pretexto para desenhos que ocupam toda a folha, ou mesmo várias.

A igreja de São Pedro dos Clérigos no Porto é objeto de detalhado estudo que distribui em uma única folha, torre, fachada, planta elíptica e diversos detalhes do interior.

Noutros, uma única folha abriga um grande número de temas e de cidades. Quando isso ocorre, linhas sinuosas separam os vários temas e cidades entre si. Interessante verificar que a medida que os blocos iam chegando ao fim, as folhas passavam a ser mais intensamente desenhadas com um número maior de informações registradas numa mesma folha. A quantidade de coisas importantes a serem lembradas, que iam sendo encontradas nos percursos, era enorme e a preocupação de não deixar de registrá-las, enquanto um novo bloco não fosse encontrado e comprado, explicam como os desenhos vão ficando menores nas páginas finais dos blocos.

Os desenhos permitem o registro do que de essencial quer-se lembrar. Muitas das vezes eles são bastante simplificados, com poucos traços que apesar disso fazem uma verdadeira anamnese arquitetônica. O conjunto de escadas barrocas que dão acesso ao Santuário de Nossa Senhora da Encarnação em Leiria seria minuciosamente registrado na sua sequencia de platôs para se concluir numa anotação a margem se tratar de obra medíocre.

$\mathrm{Na}$ arquitetura religiosa, os azulejos revestindo as naves e capelas, os forros em caixotões de madeira, os púlpitos autônomos sobre coluna, os retábulos de pedra 
Figura 1: São Pedro dos Clérigos, Porto. Fonte: Acervo da Fundação Casa de Lucio Costa. renascentistas e a talha barroca mais caprichosa, muito adequadamente denominada por ele de "valente", compõem um universo que, pela grande quantidade, muitas vezes parecia-lhe repetitivo, mas que inesperadamente podia ressurgir encantador na sua qualidade plástica. No caso da talha há uma espécie de permanente exercício de comprovação da hipótese de periodização lançada no seu texto sobre a arquitetura religiosa jesuítica. Isso vai estar muito presente nos desenhos, onde os altares, são constantemente classificados de acordo com os quatro períodos propostos por Lucio para a talha brasileira e adaptados nos retábulos portugueses encontrados: primeira fase, de primeira para segunda, segunda com traços da terceira, plena terceira fase. Outro objeto de constante registro nas anotações de Lucio são as capelas alpendradas. Muito difundidas no Brasil dos primeiros séculos de colonização e bem registradas na vasta iconografia dos holandeses sobre Pernambuco, eram pouquíssimas as que ainda conservavam os seus respectivos alpendres nas primeiras décadas do século XX. A refração

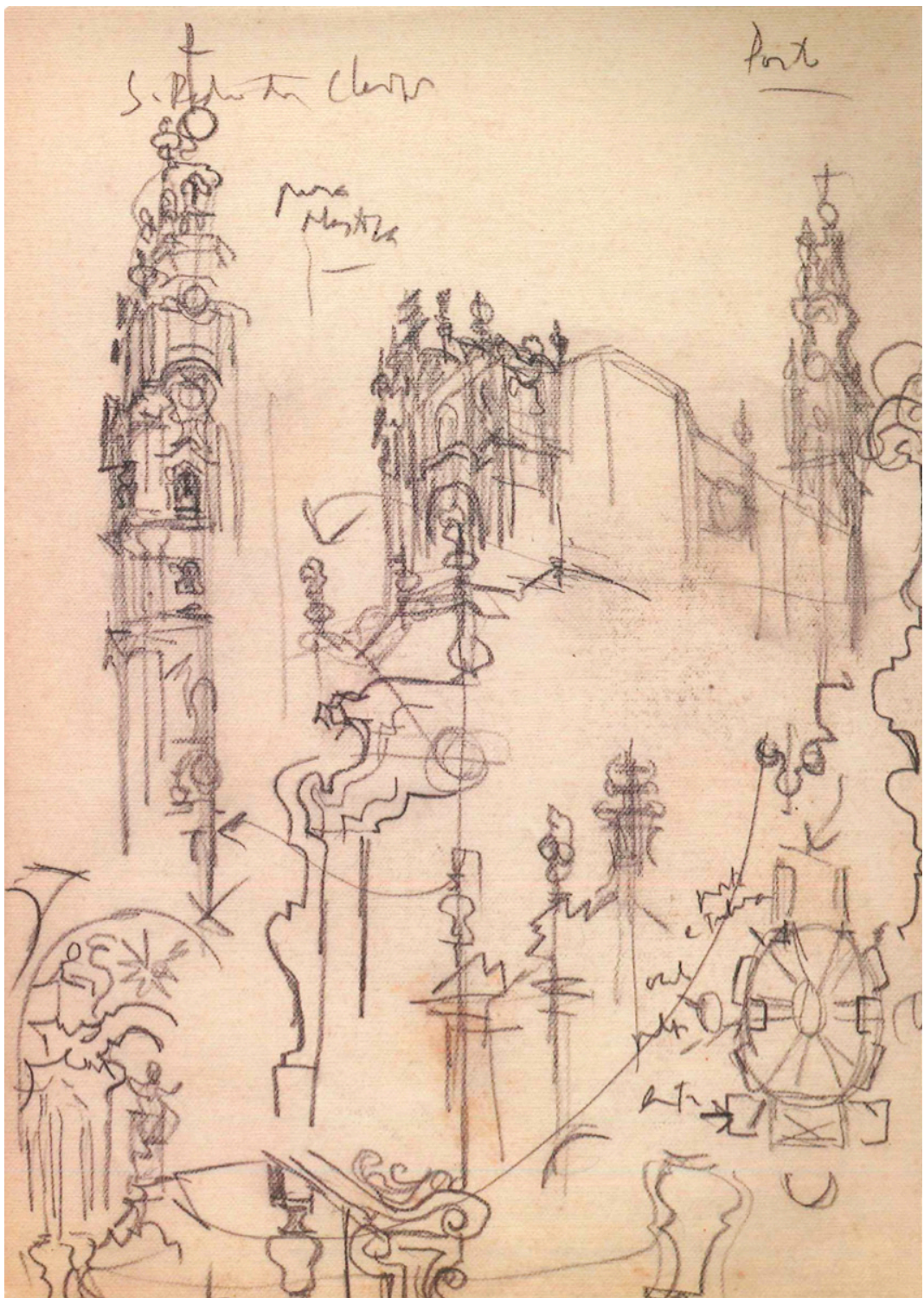




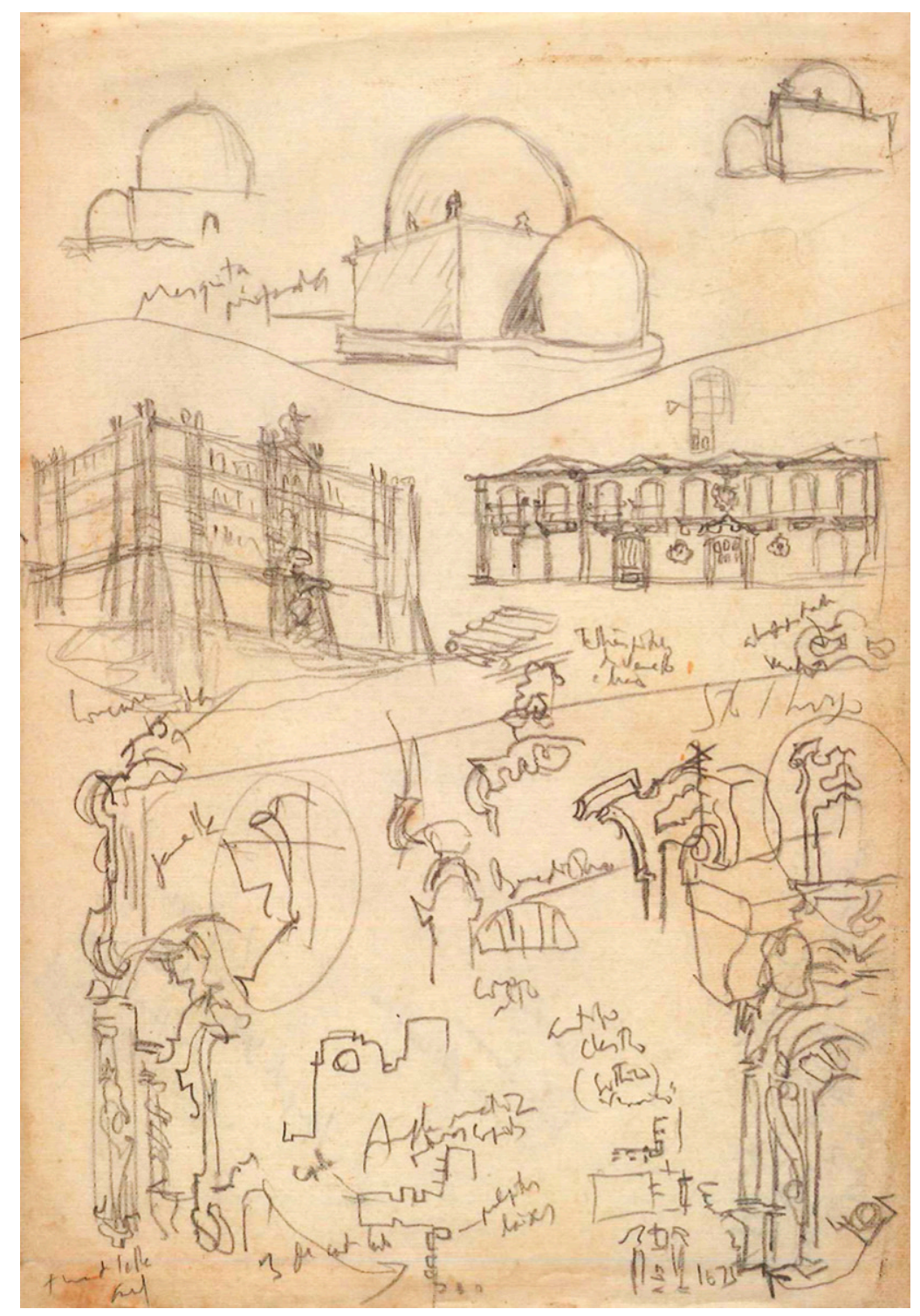

Figura 2: No alto a Capela seiscentista de Nossa Senhora do Socorro, denominada por Lucio Costa de "mesquita profanada", ao centro o monumental convento de Santa Clara e casa setecentista dos Vasconcellos, todos em Vila do Conde, na metade inferior da folha desenhos da talha da igreja beneditina de Santo Tirso. Fonte: Acervo da Fundação Casa de Lucio Costa. ou não dos alpendres das capelas seiscentistas era um tema de acalorado debate no SPHAN dos anos 1940 e 1950. Consequência deste debate é a enorme atenção que Lucio dará ao registro dos alpendres encontrados no caminho. Há portanto uma permanente relação entre o visto e desenhado em Portugal e a lembrança do Brasil. Alpendres de igrejas, capelas e casas são registrados nos desenhos, para lembrar dos problemas que se colocavam no cotidiano da restauração no IPHAN daqueles anos; como as dúvidas acerca da reconstituição destes nas igrejas da Bahia, de Cabo Frio, etc. Encontrar o alpendre de uma casa desenhada nas proximidades da igreja matriz de Pombal, com a anotação da "seção quadrada" dos pilares, trazia certamente a memória das soluções possíveis de reconstituição do alpendre da Igreja de Montserrat em Salvador da Bahia.

Igrejas e capelas iriam ser a permanente comprovação da hipótese lançada em 1948 e levada na viagem de 1952. A mutua influência entre a colônia e o reino anotada e qualificada em várias passagens: de forma positiva com na bela igreja mineira dos 
Figura 3: Na parte superior da folha, sobrado com alpendre de pilares de seção quadrada, Pombal. Fonte: Acervo da Fundação Casa de Lucio Costa. irmão terceiros de São Francisco em Viseu; ou negativa nas observações acerca do interior da igreja do santuário de Bom Jesus de Braga, com o seu interior ordinário,e o baldaquinho baiano medíocre.

As influências ocorrem também nas relações entre as várias províncias visitadas que faz com que no Alentejo, diante da portada do antigo Real Celeiro do Monte da Piedade, ele anote em Évora também há disto, numa clara alusão da influência no sul do exuberante barroco minhoto; ou no contexto europeu apontando uma influencia espanhola nas igrejas de Trás-os-Montes com sineira no meio da fachada, e o caso mais curioso de todos da estranha releitura do renascimento italiano na fachada da Igreja de Nossa Senhora da Graça em Évora, descrita por Lucio como sendo louca varrida com pinta miguelangelesca.

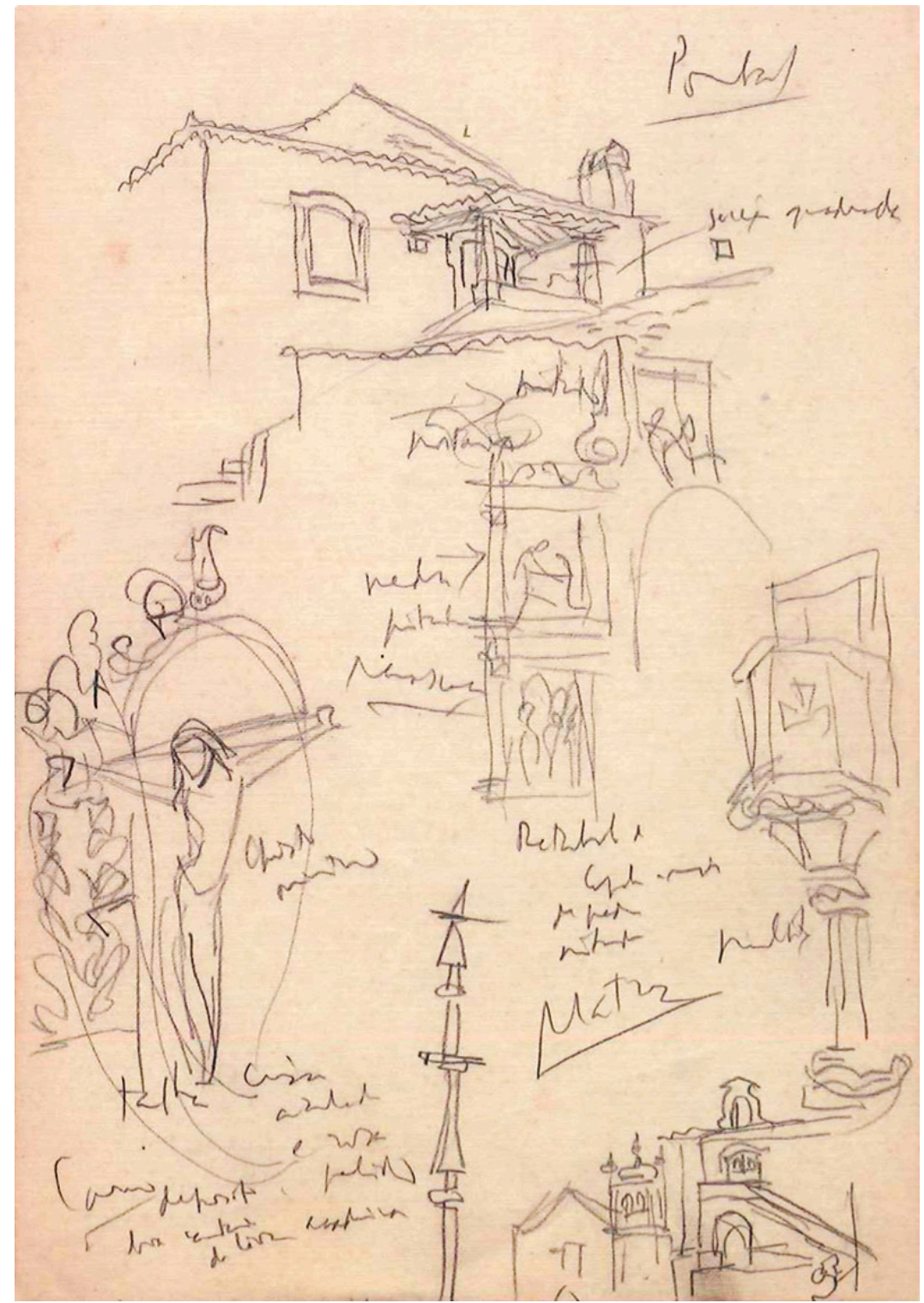


Figura 4: Sistema de dupla calha para prolongamento do beiral, Setubal. Embaixo a igreja de Santa Maria de Setubal obra renascentista de Antonio Rodrigues. Lucio anota o paladianismo da portada. Fonte: Acervo da Fundação Casa de Lucio Costa.

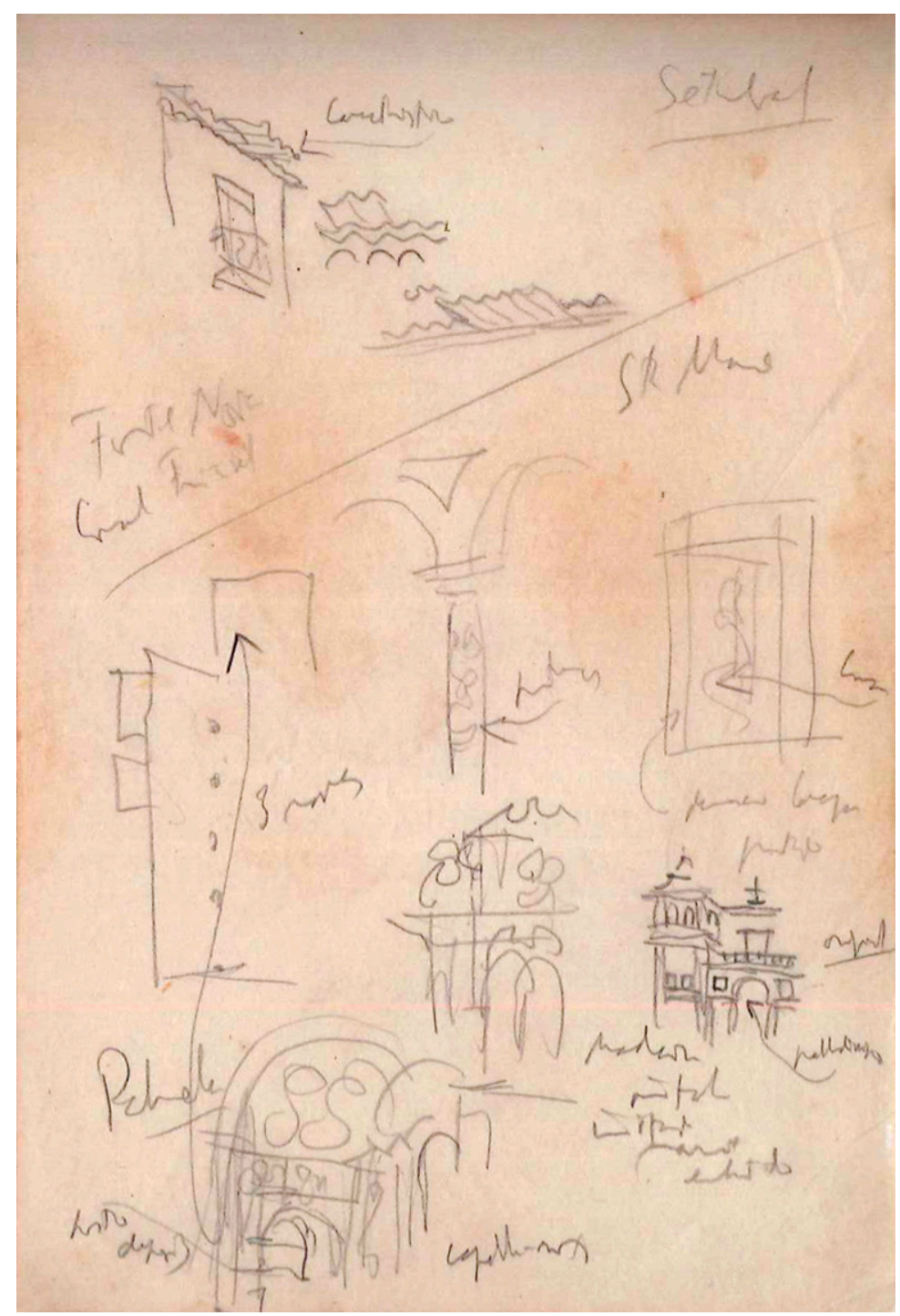

Nos detalhes construtivos está também presente a constatação da circulação de saberes e modelos. Em Santarém ele que várias das grades tem os pormenores típicos dos mais antigos encontrados em janelas maranhenses, ou em Setubal desenha a superposição de telhas na terminação do telhado, fato único em Portugal, e que ocorria também em São Luis do Maranhão.

Há também na identificação destes detalhes construtivos o olhar do restaurador. Como resolver uma série de questões que se punham no cotidiano de trabalho do SPHAN? Essa é uma resposta procurada no olhar que registrava nos desenhos portugueses o passado do Brasil. É este registro, essa conversa do arquiteto consigo mesmo que vai resultar nos inúmeros desenhos de entelhamentos de beiral, dos perfis de grades de madeira e ferro, e no olhar de identificação das transformação dos edifícios. É um olhar atento que vai do todo ao detalhe, estabelecendo cronologias na identificação de acréscimos - como os coros das igrejas de Azambuja e Estremoz, identificados como posteriores a nave das igrejas ou a balaustrada refeita com outro perfil, mais robusto 
Figura 5: Estudo de escadas das casas de Olhão. Fonte: Acervo da Fundação Casa de Lucio Costa. do que o original, na fachada lateral da Sé Velha de Coimbra -, e principalmente qualificando o valor plástico, ou a ausência deste, nos objetos desenhados.

A qualidade plástica da arquitetura popular encontrada no Alentejo e no Algarve faz dos registros um misto de reprodução e invenção. Há certamente um que de invenção nos estudos em poucas linhas que ele faz das escadas que conduzem as sotéias (terraços) das casas de pescadores da Vila do Olhão. O olhar de vários ângulos resulta as vezes numa espécie de escada-sapato. No sul a admiração pela qualidade plástica das casas simples se processa também no registro do cotidiano dessas aldeias, como do processo de caiação das casas em Serpa. Em que ele descreve os períodos em que esta era feita, as roupas das pessoas caiando as casas e os hábitos que the soam curiosos como as pessoas pedem com licença antes de fechar a porta.

No norte também a arquitetura popular de pedra seria objeto de inúmeros desenhos. Nestes casos não há tanto a preocupação com a identificação do Brasil nessas arquiteturas. Há o encantamento, como em Olhão pela qualidade plástica das casas populares. Aquilo que era para Lucio Costa a grande contribuição do mundo português para a arquitetura. Em Oulela de Bastos, uma pequena aldeia no norte, uma casa de pedra chama a atenção de Lucio Costa. É muito interessante, pois o que chama de fato a atenção dele é a disposição das grandes lajes de pedra, numa das paredes externas da casa. É esta sequência de pedras mais curtas e mais compridas,

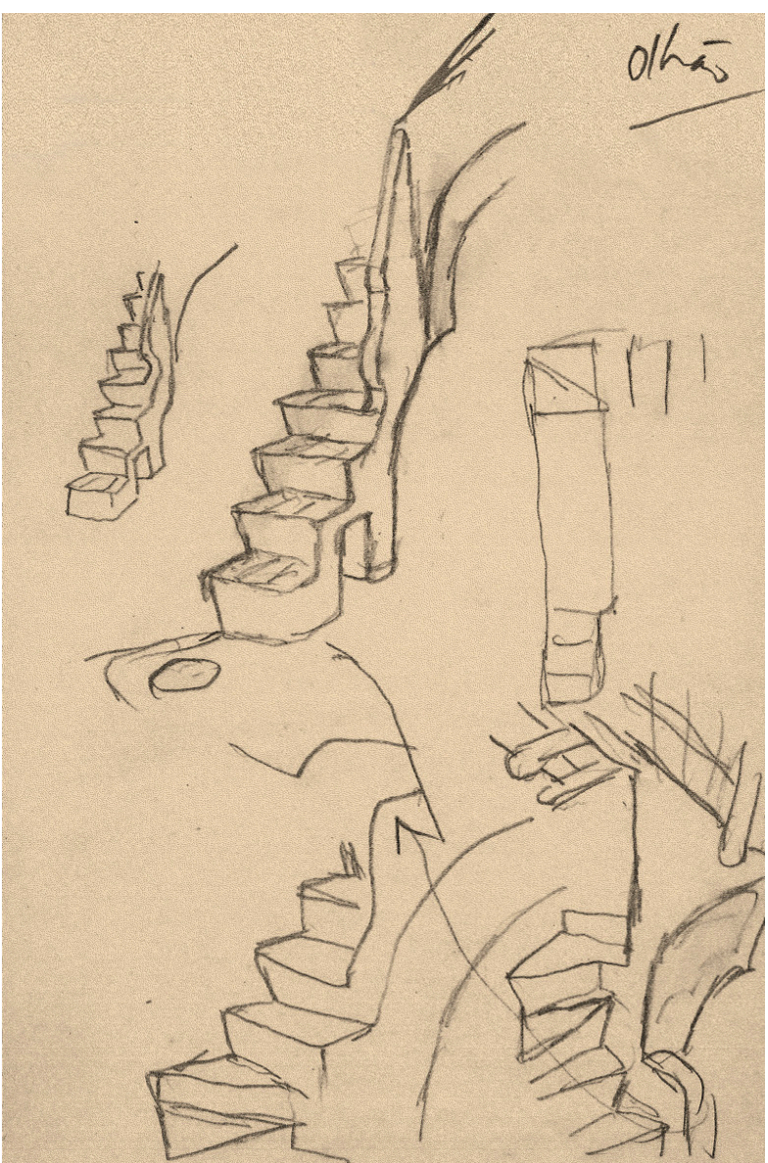


Figura 6: Na parte superior da folha, detalhe de casa de pedra em Oulela de Bastos. Fonte: Acervo da Fundação Casa de Lucio Costa.

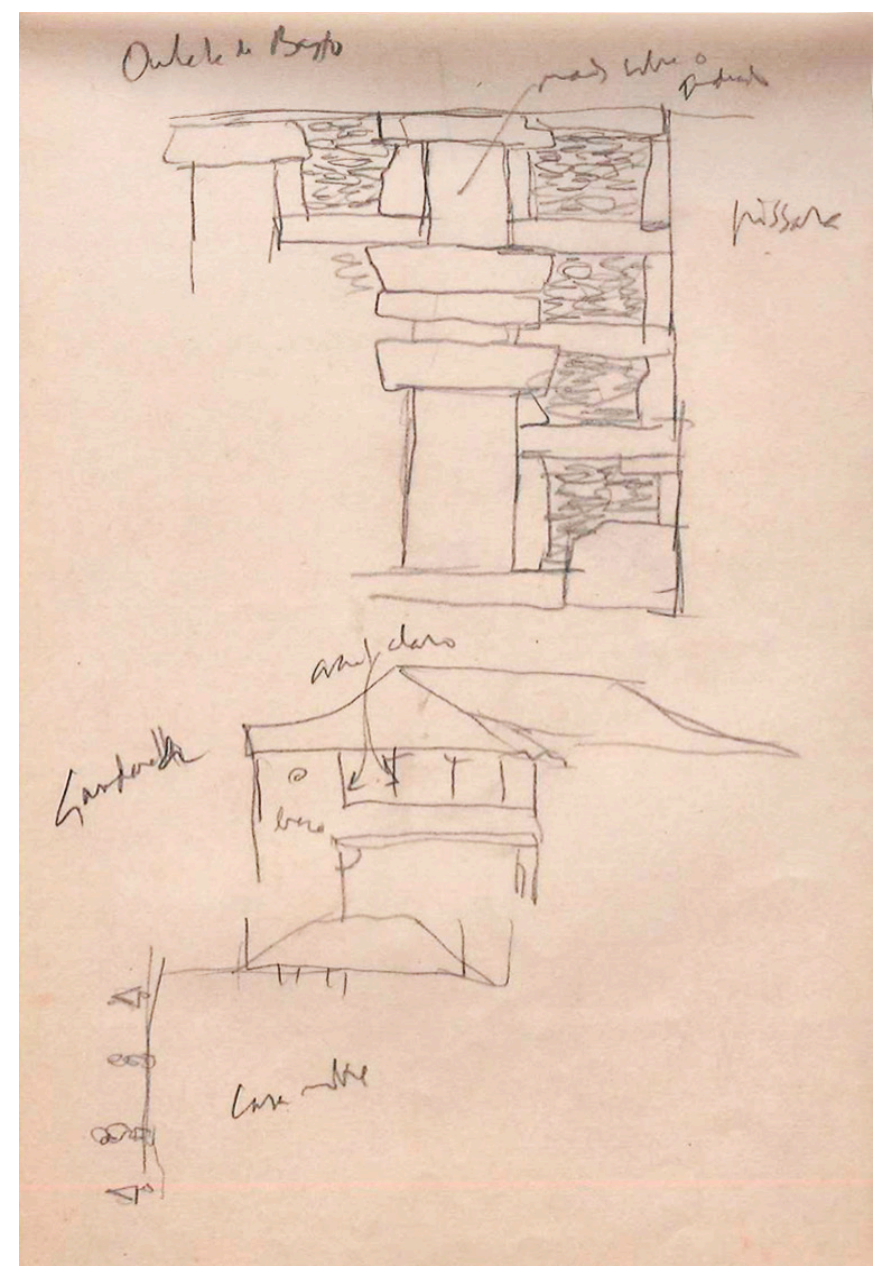

de fato é muito bonita, que será registrado e é um bom exemplo de que muitas vezes o essencial da arquitetura está no acerto da proporção dos elementos. É essa busca de qualidade plástica que para Lucio distingue a arquitetura, da construção. São portanto estes elementos que foram anotados durante a viagem de Lucio Costa a Portugal em 1952. Essas anotações exemplificam extraordinariamente o papel do desenho para compreender a arquitetura e realizar o projeto.

\section{Referências bibliográficas}

FUNDAÇÃO CASA DE LUCIO COSTA. <https://www.casadeluciocosta.org/> (acesso em 14 de agosto 2012).

MASSIRONI, Manfredo. Ver pelo desenho: aspectos técnicos, cognitivos, comunicativos. Lisboa: Ed. 70, 1983.

MATTOSO, J. (org.). América do Sul: Património de origem portuguesa no mundo. Lisboa: Editora: Fundação Gulbenkian, 2010.

PESSôA, José Simões de Belmont (Org.). Lucio Costa: documentos de trabalho. Rio de Janeiro, Iphan, 1999 